\title{
Glucose transporter and hypoxia-associated gene expression in the mammary gland of transition dairy cattle
}

\author{
S. A. Mattmiller, ${ }^{\star}$ C. M. Corl, ${ }^{\star}$ J. C. Gandy, ${ }^{\star}$ J. J. Loor, $†$ and L. M. Sordillo*1 \\ *Department of Large Animal Clinical Sciences, Michigan State University, East Lansing 48824 \\ †Department of Animal Sciences and Division of Nutritional Sciences, University of Illinois at Urbana-Champaign 61820
}

\begin{abstract}
Glucose is an important energy substrate, especially needed by dairy cows postpartum to support the onset of lactation. The prioritization and regulation of glucose uptake is accomplished, in part, by changes in expression of cellular glucose transport molecules (GLUT) within the mammary gland. The objectives of this study were to (1) evaluate the expression and cell-type specific localization of GLUT and hypoxiaassociated genes that may regulate GLUT expression over the transition period and through lactation in bovine mammary tissue and (2) determine functionality of GLUT on primary bovine mammary endothelial cells (BMEC). Mammary tissue biopsies were taken from cows at $15 \mathrm{~d}$ before calving and again at 1, 15, 30, 60, 120 , and $240 \mathrm{~d}$ post-parturition for quantitative realtime PCR analysis of GLUT and hypoxia-associated genes. Additional mammary tissue samples were used to localize GLUT within the cells of the lobulo-alveolar system via fluorescence microscopy. Cultures of primary bovine mammary endothelial cells were used to confirm the functionality of GLUT with a fluorescent glucose analog uptake assay. Significant increases in GLUT1 gene expression were observed during early lactation, whereas both GLUT3 and GLUT4 gene expression increased during late lactation. The gene expression for 2 receptors of vascular endothelial growth factor increased significantly during early lactation and remained increased throughout lactation when compared with gene expression during the transition period. All GLUT were detected on cultured BMEC and were capable of internalizing glucose through GLUT-mediated mechanisms. These data suggest mammary vascular tissues express GLUT during lactation and BMEC express functional glucose transporters. A better understanding of glucose uptake at the endothelial level may prove to be critical to improve glucose absorption from the blood for utilization by mammary epithelial cells.
\end{abstract}

Received October 15, 2010.

Accepted February 2, 2011.

${ }^{1}$ Corresponding author: Sordillo@msu.edu
Key words: glucose transport molecules (GLUT), hypoxia, transition period, endothelium

\section{INTRODUCTION}

Glucose is an important energy-providing nutrient for dairy cattle, especially during the transition period. In the mammary gland, glucose is required to provide energy for synthesis of milk constituents, but particularly for the synthesis of lactose. Lactose is responsible for balancing the osmolarity of mammary secretions, ultimately determining total milk production (Cant et al., 2002 ). With the onset of lactation, approximately $85 \%$ of total body glucose is partitioned to the mammary gland to sustain copious milk secretion (Bickerstaffe et al., 1974). However, the molecular mechanisms behind glucose uptake in the mammary gland during times of increased production demands are still unknown.

The extensive mammary vascular system controls blood flow and delivery of milk constituents, such as glucose, to mammary tissues. Anatomical features of the mammary microvasculature were described extensively in rodents and to a lesser extent in the bovine (Prosser et al., 1996). The mammary capillary network forms a basket-like structure around alveoli and this is the primary site of exchange of metabolites from blood to tissue. Microscopic examination of human (Stirling and Chandler, 1976; Naccarato et al., 2003) and rodent (Matsumoto et al., 1992) mammary glands suggest that the capillary endothelium is largely continuous with some minor areas of fenestration. Rodent and bovine mammary gland capillaries exhibit numerous marginal folds and microvillus processes beginning from late pregnancy to peak lactation, thus increasing the surface area for the exchange of molecules from blood to tissue (Matsumoto et al., 1992; Abdul Awal et al., 1996; Ludewig, 1996a,b). The mechanisms by which glucose moves across the capillary wall and into the interstitial fluid are not clear.

For specialized regions of the body, known as bloodtissue barriers, a facilitated mechanism of transport was suggested as a way glucose is transported from the blood to the tissue (Takata and Hirano, 1997). Glucose 
transport through these blood-barrier tissues is facilitated by a group of membrane-bound, protein molecules known as glucose transporters (GLUT). Several isoforms of GLUT molecules were identified in the bovine mammary gland, including GLUT1, GLUT3, and GLUT4. Commonly expressed in blood-tissue barriers, GLUT1 is the most abundant transporter found in bovine mammary tissue (Zhao et al., 1993) and GLUT3 has been associated with cells that require rapids bursts of energy (Pantaleon et al., 1997), whereas GLUT4 is an insulin-sensitive glucose transporter (Zhao et al., 1993). Expression and cellular localization of GLUT are regulated by several stimuli such as hypoxia to meet the demand for glucose (Zhao and Keating, 2007).

Increased metabolic activities in the mammary gland during the transition period result in a lowered oxygen tension (Reynolds, 1967). Prolonged low oxygen tension, or hypoxia, can stimulate GLUT1 expression in bovine endothelial cells (Takagi et al., 1998). Increased glucose uptake is a common response of cells experiencing hypoxia. Hypoxic conditions then stabilize an important transcription factor, hypoxia-inducible factor-1 (HIF-1), which is expressed in numerous cell types and upregulates various survival and repair genes, through binding to the hypoxia response element in the genome. Hypoxia-inducible factor- 1 has 2 subunits: HIF-1 $\beta$, which is constitutively expressed, and HIF-1 $\alpha$, which is stabilized under hypoxic conditions (Semenza, 2004). Loike et al. (1992) demonstrated that under conditions of prolonged hypoxia, synthesis and expression of GLUT1 are increased in bovine endothelial cells. Hypoxia-inducible factor-1 is also responsible for the upregulation of angiogenic factors such as vascular endothelial growth factor (VEGF), which function to restore vascular homeostasis during hypoxic conditions (Semenza, 2004).

Angiogenesis induced by VEGF increases oxygen availability in the endothelium, thereby alleviating hypoxia. Vascular endothelial growth factor stimulates endothelial growth by binding to cell-surface receptors, known as FMS-like tyrosine kinase (FLT-1) and kinase domain receptor (KDR; Ferrara et al., 2003). Vascular endothelial growth factor binding initiates specific signaling cascades within the endothelial cell, inducing the release of growth factors and stimulating cellular proliferation (Ferrara et al., 2003). Additionally, when bovine retinal endothelial cells were treated with VEGF, GLUT1 expression significantly increased (Sone et al., 2000). However, a potential association between VEGF and GLUT1 expression in mammary tissues has yet to be determined.

Several studies have documented a progressive increase in GLUT1 expression in whole tissue and mammary epithelial cells during the transition period in dairy cows (Zhao et al., 1996; Komatsu et al., 2005; Zhao and Keating, 2007). However, little is known about GLUT expression over the entire lactation cycle. Additionally, GLUT expression and function is not understood in other cell types of the bovine mammary gland such as the vascular endothelium, which is critical in the uptake of nutrients from the bloodstream. Because glucose uptake from the blood is a crucial step required for milk production, it is essential to establish expression and function of GLUT at the whole-tissue and cellular level. Furthermore, because the transition period is associated with increased metabolism and hypoxia in the mammary gland (Reynolds, 1967), it is pertinent to identify possible links between HIF-1 and VEGF expression, and their correlation with GLUT expression. Therefore, the main objective of this study was to describe for the first time, changes in both GLUT and hypoxia-associated gene expression during the lactation cycle and to determine if bovine mammary vascular endothelial cells (BMEC) express functional GLUT.

\section{MATERIALS AND METHODS}

\section{Animals and Tissue Samples}

Four multiparous (third or greater lactation) Holstein dairy cows from the University of Illinois Dairy Cattle Research Unit were used. Percutaneous biopsies from each cow were obtained from the right or left rear quarter of the mammary gland at approximately $15 \mathrm{~d}$ before calving ( $13 \mathrm{~d} \pm 3 \mathrm{~d}$ ) and again at 1, 15, 30, 60, 120 , and $240 \mathrm{~d}$ following calving as described previously (Bionaz and Loor, 2007). Health was monitored post-surgery by recording rectal temperature, milk yield, and feed intake daily for $7 \mathrm{~d}$. Surgical clips were removed $7 \mathrm{~d}$ post-biopsy. No incidences of mastitis were detected in any cow during the $7 \mathrm{~d}$ post-surgery. All procedures were conducted under protocols approved by the University of Illinois Institutional Animal Care and Use Committee.

\section{Quantitative Real-Time PCR}

Total RNA was isolated from bovine mammary tissue. The RNA was DNase digested using the RNaseFree DNase Set (Qiagen, Valencia, CA), whereas cDNA was synthesized using the High Capacity cDNA Reverse Transcriptase Kit with RNase Inhibitor (Applied Biosystems, Foster City, CA). All of the primers used in the present study (Table 1) were derived from the Bos taurus genome (GenBank). Quantitative real-time PCR (qPCR) was carried out in a 7500 Fast Real-Time PCR system (Applied Biosystems) using custom-designed TaqMan minor groove binding probes from Ap- 
MATTMILLER ET AL.

Table 1. Gene targets and primer sequences for quantitative real-time PCR

\begin{tabular}{|c|c|c|c|}
\hline Target & Accession no. & Sequence type & Sequence $\left(5^{\prime}\right.$ to $\left.3^{\prime}\right)$ \\
\hline \multirow[t]{3}{*}{ GLUT1 } & \multirow{3}{*}{ NM_174602 } & Forward & CGGCTGCCCTGGATGTC \\
\hline & & Reverse & GCCTGGGCCCACTTCAAA \\
\hline & & Probe & ATGGCCACAATGCTCA \\
\hline \multirow[t]{3}{*}{ GLUT3 } & \multirow[t]{3}{*}{ XM_001256170.1 } & Forward & CAAGTCACAGTGCTAGAGTCTTTC \\
\hline & & Reverse & GGAGAGCTGGAGCATGATAGAGAT \\
\hline & & Probe & CCGGCAACCCATCATT \\
\hline \multirow[t]{3}{*}{ GLUT4 } & \multirow[t]{3}{*}{ BC114082.1 } & Forward & GTCAACACAGTCTTCACCTTAGTCT \\
\hline & & Reverse & CCAGGCCCAGGAGATGGA \\
\hline & & Probe & CCCAGCCCGTTCCAC \\
\hline \multirow[t]{3}{*}{ HIF-1 $1 \alpha$} & \multirow[t]{3}{*}{ NM_174339 } & Forward & CCACGAGGAAATGAGAGAAATGCTT \\
\hline & & Reverse & CCGCTGTGTATTTTGCTCTTTACC \\
\hline & & Probe & CACAAGGCCATTTCTG \\
\hline \multirow[t]{3}{*}{ VEGF } & \multirow[t]{3}{*}{ NM_174216 } & Forward & GCAGAAGGAGGGCAGAAACC \\
\hline & & Reverse & CTGCGCTGGTAGACATCCAT \\
\hline & & Probe & CCACGAAGTGGTGAAGTT \\
\hline \multirow[t]{3}{*}{ FLT-1 } & \multirow[t]{3}{*}{ X94263 } & Forward & TGCGAGCACCCGAGTATG \\
\hline & & Reverse & GCCAGCAGTCCAACATGATCT \\
\hline & & Probe & ACGCCTGAAATCTACC \\
\hline \multirow[t]{3}{*}{ KDR } & \multirow[t]{3}{*}{ X94298 } & Forward & CATGGGCTCCGTTCTTTATGTGTAT \\
\hline & & Reverse & GCTGGTCGCTAACAGAAGCAATAA \\
\hline & & Probe & ACGGAGACCTGTAATCTTGAAC \\
\hline \multirow[t]{3}{*}{ B-actin } & \multirow[t]{3}{*}{ NM-173979 } & Forward & CCGCCCCGCTAGCA \\
\hline & & Reverse & AACTGGTTGCGGTGTCGA \\
\hline & & Probe & CCTTCGCCGCTCCGC \\
\hline \multirow{3}{*}{ RPS9 } & \multirow{3}{*}{ XM_864261 } & Forward & GGCGGCTCGTCCGTATC \\
\hline & & Reverse & AATCTTCAGGCCCAGGATGTAATC \\
\hline & & Probe & CCCTCATCCAGCACCC \\
\hline \multirow[t]{3}{*}{ RPS15 } & \multirow[t]{3}{*}{ XM_585783 } & Forward & AAAGAGCAGCTTATGAGCAAGGT \\
\hline & & Reverse & TTGACAGTCAAGGCAACAATTTGAG \\
\hline & & Probe & TCCTTCGGGTTTTCC \\
\hline
\end{tabular}

plied Biosystems. The PCR was performed in triplicate using a $10-\mu \mathrm{L}$ reaction mixture per well, containing 5 $\mu \mathrm{L}$ of TaqMan Fast Universal PCR Master Mix $(2 \times$, Applied Biosystems), $0.5 \mu \mathrm{L}$ of $(20 \times)$ Custom TaqMan Gene Expression Assay Mix (Applied Biosystems), 50 ng of cDNA, and the balance was nuclease-free water. Targeted genes were amplified with the reaction mixture described above. A $(20 \times)$ Custom TaqMan Gene Expression Assay Mix for bovine $\beta$ actin, ribosomal protein 9, and ribosomal protein 15 was generated by Applied Biosystems as an endogenous control. The thermal cycling conditions for fast 2-step PCR were used: stage 1 , enzyme activation, $95^{\circ} \mathrm{C}$ for $20 \mathrm{~s}$; stage 2 , $95^{\circ} \mathrm{C}$ for $3 \mathrm{~s}$; stage $3,60^{\circ} \mathrm{C}$ for $30 \mathrm{~s}$; with 40 replications through stages 2 and 3. Quantification was carried out with the relative quantification method (Livak and Schmittgen, 2001). The abundance of target genes, normalized to the average of the 3 endogenous control genes and relative to a calibrator, are calculated by $2^{-\Delta \Delta \mathrm{Ct}}$, where $\mathrm{Ct}$ is the cycle number at which the fluorescence signal of the product crosses an arbitrary threshold set with exponential phase of the PCR and $\Delta \Delta \mathrm{Ct}$ $=\left(\mathrm{Ct}_{\text {target gene UNK }}-\mathrm{Ct}_{\text {average of } 3 \text { endogenous control genes UNK }}\right)$ - $\left(\mathrm{Ct}_{\text {target gene } \mathrm{CAL}}-\mathrm{Ct}_{\text {average of } 3 \text { endogenous control genes } \mathrm{CAL}}\right)$, where UNK $=$ unknown sample and $\mathrm{CAL}=$ calibrator sample. The averaged abundance of target genes at 15 d before calving was used as the calibrator sample for all subsequent samples.

\section{BMEC Culture}

Endothelial cells were isolated from the bovine mammary artery by collagenase digestion and purified through cloning techniques using the limited dilution method by Aherne et al. (1995). Briefly, isolated cells were grown in a $\mathrm{T} 25$ culture flask at $37^{\circ} \mathrm{C}$ with $5 \%$ $\mathrm{CO}_{2}$. Once cells reached 75 to $90 \%$ confluence, they were harvested and transferred into a 96-well tissue culture plate at a dilution of 0 to 2 cells/well. Once confluent, these cells were consecutively passed in 24well plates, 6 -well plates, and T25 culture flasks before cryopreservation. The purity of the cloned endothelial cells were confirmed with uptake of acetylated low-density lipoprotein labeled with $1,1^{\prime}$-dioctadecyl-3,3,3',3'tetramethylindocarbocyanine perchlorate and positive staining for von Willebrand factor (A0082, DakoCytomation, Carpinteria, CA), as described previously (Aherne et al., 1995). The purified BMEC were then cultured in F-12K medium containing $5 \%$ fetal bovine serum (FBS), antibiotics and antimycotics $(100 \mathrm{U} / \mathrm{mL})$, heparin $(100 \mu \mathrm{g} / \mathrm{mL})$, insulin $(10 \mu \mathrm{g} / \mathrm{mL})$, transferrin $(5 \mu \mathrm{g} / \mathrm{mL})$, and sodium selenite $(10 \mathrm{ng} / \mathrm{mL})$. 


\section{Immunofluorescence}

Staining of Whole Mammary Tissue. Bovine mammary tissues isolated from slaughtered cows within the first $30 \mathrm{~d}$ of lactation were analyzed for expression of glucose transporters and hypoxia-associated genes in by immunofluorescence. Bovine mammary tissue samples were washed with sterile PBS and fixed in $10 \%$ buffered formalin for $18 \mathrm{~h}$ before being embedding in paraffin. Serial sections were stained with the following mouse monoclonal antibodies: GLUT1 (ab40084; Abcam, Cambridge, MA), GLUT3 (sc-74497; Santa Cruz Biotechnology, Santa Cruz, CA), GLUT4 (ab 48547; Abcam), HIF1a (MA1-16504; Thermo Scientific, Rockford, IL), VEGF (MA1-16626; Thermo Scientific), KDR (sc-6251; Santa Cruz Biotechnology), or rabbit polyclonal FLT-1 (sc-316; Santa Cruz Biotechnology) using corresponding secondary antibodies conjugated to NovaRED (Vector Laboratories, Burlington, CA). Samples were then stained with von Willebrand factor (A0082, DakoCytomation) as a positive marker for endothelial cells using a corresponding secondary antibody conjugated to fluorescein isothiocyanate (FITC). Sections were pre-treated by heat-induced epitope retrieval in citrate buffer for $30 \mathrm{~min}$ at $100^{\circ} \mathrm{C}$ before incubating with primary antibodies for $60 \mathrm{~min}$.

Staining of Cultured BMEC. For experimental use, BMEC were seeded at a concentration of $4 \times 10^{5}$ cells per well in a 6 -well plate containing glass coverslips. At approximately $18 \mathrm{~h}$ after seeding, coverslips were washed with $1 \times$ PBS and blocked with $1 \%$ solution of BSA in $1 \times$ PBS. Coverslips were washed with $1 \times$ PBS, incubated on ice for $1 \mathrm{~h}$ with mouse monoclonal antibodies against GLUT1 (ab40084; Abcam), GLUT3 (sc-74497; Santa Cruz Biotechnology), and GLUT4 (ab 48547; Abcam), washed with $1 \times$ PBS and fixed with $2 \%$ formaldehyde in PBS for 15 min. Coverslips were washed, incubated on ice with Alexa Fluor 488 goat anti-mouse IgG (A-10680, Invitrogen, Carlsbad, CA) for $30 \mathrm{~min}$ and mounted on glass slides with ProLong Gold antifade reagent with 4',6-diamidino-2-phenylindole (DAPI; P36935; Invitrogen). Slides were observed on a Zeiss Axiovert 200 microscope (Zeiss, Thornwood, NY). Images were captured using Zeiss AxioVision Product Suite (Zeiss). Specificity for each antibody was established using a Western blot.

\section{Glucose Uptake Assays}

The BMEC were seeded at a concentration of $4 \times 10^{5}$ cells per well in a 6-well plate, in duplicate, and incubated at $37^{\circ} \mathrm{C}$ overnight. The uptake of the fluorescent glucose analog, 2-(N-(7-nitrobenz-2-oxa-1,3-diazol-4-yl) amino)-2-deoxyglucose (2-NBDG; N13195; Invitro- gen) and a specific GLUT inhibitor, cytochalasin B (BML-T108-0005; Enzo Life Sciences, Plymouth Meeting, PA) were tested. First, culture media was removed and the cells were washed with Hank's Balanced Salt Solution (HBSS). Based on preliminary studies that determined optimal dose and timing, BMEC were incubated with $100 \mu M$ 2-NBDG in culture media for 20 min as described previously (Gaudreault et al., 2008). Cells cultured in media without 2-NBDG were used as negative controls. To assess the amount of glucose uptake that could be attributed to GLUT, BMEC were treated with $10 \mu M$ cytochalasin $\mathrm{B}$, a competitive inhibitor (Estensen and Plagemann, 1972), for $10 \mathrm{~min}$ before the addition of $100 \mu M$ 2-NBDG. All cells were washed 4 times with HBSS and observed on a Zeiss Axiovert 200 microscope. Images were captured using Zeiss AxioVision Product Suite. Fluorescence intensity was calculated using the hand measure tool option by outlining several cells in the viewed field. Fluorescence intensity values obtained for each treatment were subtracted from values obtained from an empty well (background fluorescence). The corrected values were then calculated as a fold increase over the control well seeded with cells without the addition of 2-NBDG.

\section{Statistical Analyses}

All statistical analyses were conducted using SAS, version 9.1.2 for Windows (SAS Institute Inc., Cary, NC). Pearson correlation coefficients were computed to determine relationships between GLUT and hypoxiaassociated-genes. The effect of lactation stage $(-15,1$, $15,30,60,120$, and $240 \mathrm{~d}$ relative to expected calving date) on the relative abundance of mRNA in the mammary tissue (using cow as the random factor), and the function of GLUT on BMEC using a 2-NBDG uptake assay (cell clone as the random factor) were tested by the MIXED procedure of SAS. Protected least significant difference was used to compare least squares means and data are reported as least squares means \pm standard error of the means. Significant differences were declared at $P \leq 0.05$.

\section{RESULTS}

\section{Whole Mammary Tissue Gene Expression}

Glucose Transporters. For each gene evaluated, changes in expression were compared with the baseline sample obtained at $15 \mathrm{~d}$ before calving. Changes in relative mRNA abundance were apparent for all 3 glucose transporters evaluated. For GLUT1, a significant increase in expression was observed beginning at $15 \mathrm{~d}$ of lactation and peaked between 60 and $120 \mathrm{~d}$. Then ex- 
pression decreased around late lactation, back to levels that were statistically the same as those observed prepartum (Figure 1A). The mRNA abundance of GLUT3 and GLUT4, however, exhibited different expression patterns. Expression of GLUT3 reached a significant increase at $240 \mathrm{~d}$ in lactation (Figure 1B). The GLUT4 mRNA followed a similar pattern as GLUT3 and a significant increase in GLUT4 gene expression was apparent only during late lactation at $240 \mathrm{~d}$ (Figure 1C).

Hypoxia-Associated Genes. To examine changes in the transcription factor HIF-1, the mRNA abundance of the HIF-1 $\alpha$ subunit was evaluated because unlike the constitutively expressed HIF- $1 \beta$, the $\alpha$ subunit is sensitive to changes in oxygen tension. Expression values for HIF-1 $\alpha$ mRNA did not reach significance throughout the time points sampled (Figure 2). The mRNA expression for the angiogenic factor, VEGF, followed an increasing trend during early lactation, but only approached a significant increase around the time of peak lactation or $60 \mathrm{~d}(P=0.06$; Figure $3 \mathrm{~A})$. The mRNA abundance for the VEGF receptor FLT-1 significantly increased at $15 \mathrm{~d}$ and remained elevated through $240 \mathrm{~d}$ (Figure 3B). The gene expression for the other VEGF receptor, KDR, was increased significantly at $15 \mathrm{~d}$ and then again between d 60 to 240 (Figure 3C).

Gene Correlations. Pearson correlation coefficients were computed to determine relationships between glucose transporters and hypoxia-associated genes. Expression of GLUT1 was correlated significantly to FLT-1 and KDR (Table 2). When correlation coefficients were calculated for each individual sampling time point, GLUT1 showed significant correlations with several hypoxia-associated genes. At 1, 15, and 30 DIM, GLUT1 was significantly correlated with both VEGF and KDR (Table 3). Around the time of peak lactation, or 60 DIM, GLUT1 was significantly correlated with the hypoxic transcription factor, HIF1 $\alpha$. Into late lactation, 120 DIM, GLUT1 was significantly correlated with VEGF (Table 3).

\section{Immunofluorescence}

Whole Mammary Tissue. To localize the expression of glucose transporters and hypoxia-associated genes on the endothelium within whole tissue samples, dual staining experiments were performed using fluorescence microscopy. Regions in the whole-tissue samples that contained capillary beds were evaluated for protein expression. Endothelial cells identified within whole tissue expressed GLUT1 and GLUT3 (Figure 4). Additionally, regions containing endothelial cells expressed of HIF1 $\alpha$, FLT-1, and KDR (data not shown).

GLUT Expression on Cultured BMEC. To determine the presence of various glucose transport- ers specifically on bovine mammary endothelial cells, primary BMEC were cultured in vitro and stained with antibodies against GLUT. Using florescence microscopy, BMEC were stained with DAPI to identify nuclei of individual cells and antibodies against GLUT1, GLUT3, and GLUT4. All 3 glucose transporters were identified on cultured BMEC with uniform distribution (Figure 5). Specificity of each antibody was tested using Western blotting and GLUT1, 3, and 4 were detected in BMEC whole-cell lysates (data not shown).

\section{Glucose Uptake Assay}

To further establish presence and function of GLUT on bovine mammary endothelium, glucose uptake experiments were conducted on cultured BMECs with the fluorescent glucose analog, 2-NBDG. When 2-NBDG was added to BMEC media, a significant increase in glucose uptake occurred compared with control cells where no 2-NBDG was added (Figure 6). To show glucose transport was occurring through the activity of GLUT, a competitive inhibitor for GLUT isoforms, cytochalasin B (Estensen and Plagemann, 1972), was added to cells in addition to 2-NBDG. When cytochalasin B was added to media containing 2-NBDG, a significant decrease in glucose uptake occurred when compared with cells cultured in only 2-NBDG (Figure $6)$.

\section{DISCUSSION}

Glucose is necessary for the lactating dairy cow to sustain copious milk secretion; however, the expression patterns of GLUT over the entire lactation cycle have not been identified. Because the mammary gland cannot synthesize glucose, it is dependent on the blood for glucose supply (Threadgold and Kuhn, 1979). In bloodtissue barriers like those found in the brain, placenta, and mammary gland (i.e., the blood-milk barrier), a facilitated mechanism of transport is required to move glucose across the endothelial monolayer (Takata and Hirano, 1997). Furthermore, as regulation of GLUT is a complex process involving several stimuli, hypoxiaassociated genes were evaluated because they are associated with high metabolic activity such as that seen with the onset of lactation. Therefore, this study characterized for the first time (1) gene expression of GLUT over the entire lactation cycle, (2) correlations between GLUT and hypoxia-associated genes, and (3) expression and function of GLUT specifically on the bovine mammary vasculature.

Gene expression was characterized in the mammary gland to assess changes in GLUT over the entire lactation cycle. The glucose transporter GLUT1 was significantly 


\section{A. GLUT1}

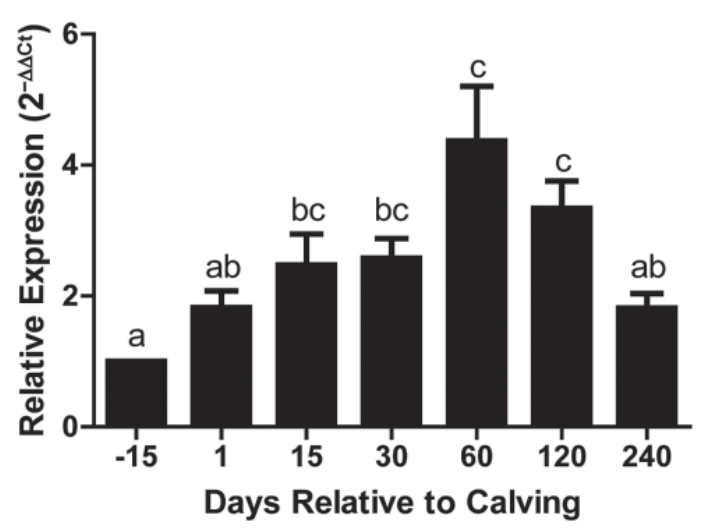

\section{B. GLUT3}

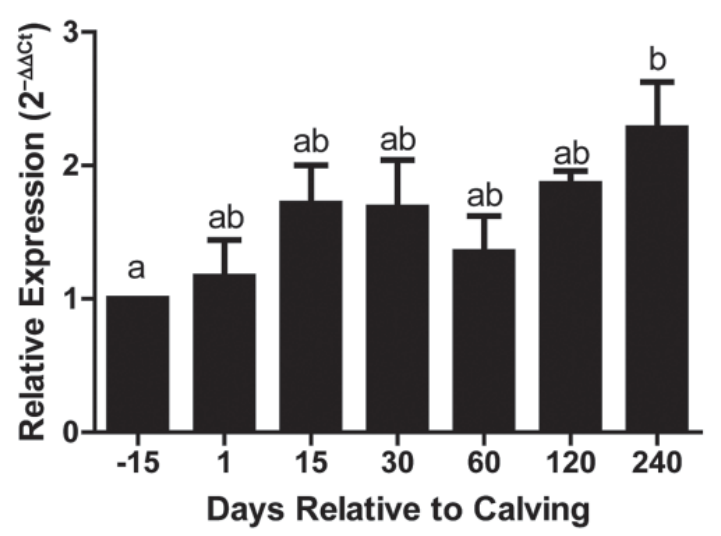

\section{GLUT4}

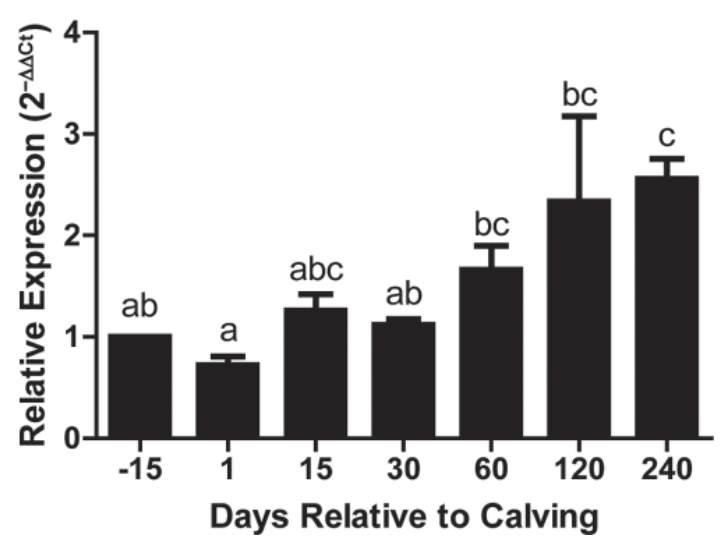

Figure 1. Alterations in mRNA abundance of glucose transporters (GLUT): (A) GLUT1, (B) GLUT3, and (C) GLUT4 in bovine mammary tissue obtained at $-15,1,15,30,60,120$, and $240 \mathrm{~d}$ relative to parturition $(\mathrm{n}=4)$. Data reported as least squares means \pm standard error of the means. Significant differences $(P<0.05)$ between days are represented with different letters. Data were analyzed by the $2^{-\Delta \Delta \mathrm{Ct}}$ method with $-15 \mathrm{~d}$ as the reference expression point, where $\mathrm{Ct}$ is the cycle number at which the fluorescence signal of the product crosses an arbitrary threshold set with exponential phase of the PCR and $\Delta \Delta \mathrm{Ct}$ $=\left(\mathrm{Ct}_{\text {target gene unknown sample }}-\mathrm{Ct}_{\text {average of } 3 \text { endogenous control genes unknown sample }}\right)-$ $\left(\mathrm{Ct}_{\text {target gene calibrator sample }}-\mathrm{Ct}_{\text {average of } 3 \text { endogenous control genes calibrator sample }}\right)$. increased within the first 2 wk following parturition through peak lactation, and then decreased during late lactation back to values statistically the same as those observed prepartum. The expression pattern described in this study coincides with previous work in the bovine mammary gland through the transition period (Zhao et al., 1996; Komatsu et al., 2005; Zhao and Keating, 2007). The main transporter (GLUT1) identified in the bovine mammary gland (Zhao and Keating, 2007), is known to be expressed on mammary epithelial cells. The expression pattern identified here suggests that GLUT1 localization within the mammary gland could make this transporter more susceptible to changes in oxygen tension, especially during times of enhanced metabolic activity. Indeed, correlations suggest a link between the hypoxic transcription factor, $\operatorname{HIF} 1 \alpha$, and GLUT1 expression around the time of peak lactation. Additionally, VEGF, which can be regulated by HIF1 $\alpha$ (Semenza, 2004), was significantly correlated with GLUT1 expression during early lactation. This finding agrees with an earlier report that found a significant increase in GLUT1 expression when bovine retinal endothelial cells were supplemented with VEGF (Sone et al., 2000). Although the correlations from this study further suggest a link between GLUT1 and VEGF expression, more research is needed to develop a direct cause-effect relationship between hypoxia-associated genes and GLUT expression in bovine mammary tissues.

Gene expression patterns of 2 additional glucose transporters, GLUT3 and GLUT4, were different when compared with GLUT1. Both GLUT3 and GLUT4 mRNA were significantly increased only into late lactation. Royer et. al (2000) showed GLUT3 gene expression did not change in response to hypoxia and GLUT4 only changed at 1 sampling time point during development in the rat brain. Increased mRNA abundance of GLUT3 and GLUT4 during late lactation found with this study is a novel finding, but could be accredited to a difference in function of GLUT isoforms within the mammary tissue during late lactation. For example, the gradual increase in GLUT4 may be a mechanism to render tissue more sensitive to the gradual increase in insulin during the later stages of lactation (Herbein et al., 1985). Moreover, GLUT3 is associated with cells requiring rapids bursts of energy (Pantaleon et al., 1997). Although conjecture, the increase in these GLUT isoforms may play a role during mammary gland remodeling toward the end of lactation. The mammary gland undergoes several changes in tissue composition over the lactation cycle, including an increase in stromal tissues and leukocytes and a concomitant decrease in secretory epithelial cells and lumen during late lactation (Sordillo and Nickerson, 1988). In the present study, 


\section{HIF-10}

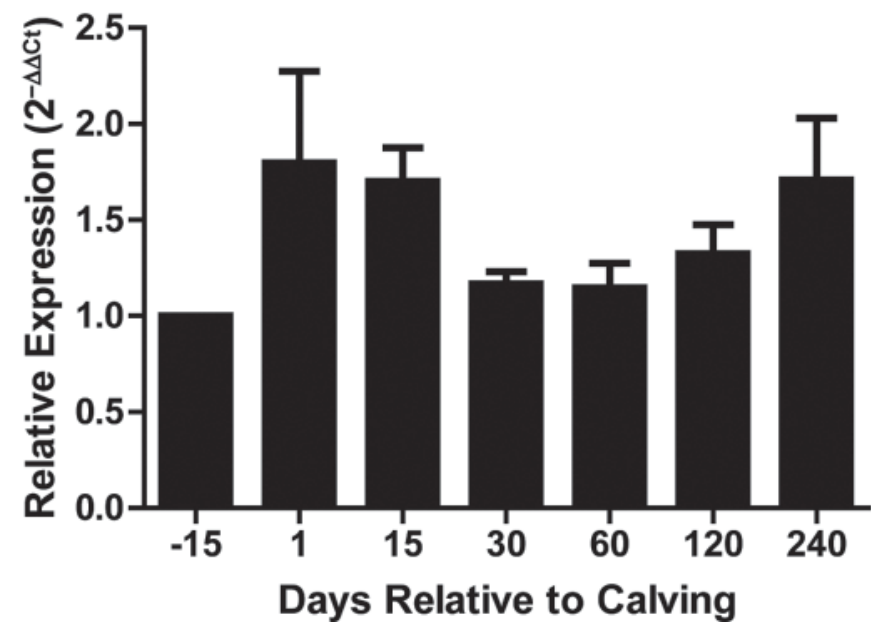

Figure 2. Alterations in mRNA abundance of hypoxia-inducible factor- $1 \alpha(\mathrm{HIF}-1 \alpha)$ in bovine mammary tissue obtained at -15 , $1,15,30,60,120$, and $240 \mathrm{~d}$ relative to parturition $(\mathrm{n}=4)$. Data were analyzed by the $2^{-\Delta \Delta \mathrm{Ct}}$ method with $-15 \mathrm{~d}$ as the reference expression point, where $\mathrm{Ct}$ is the cycle number at which the fluorescence signal of the product crosses an arbitrary threshold set with exponential phase of the PCR and $\Delta \Delta \mathrm{Ct}=\left(\mathrm{Ct}_{\text {target gene unknown sample }}\right.$ - $\left.\mathrm{Ct}_{\text {average of } 3 \text { endogenous control genes unknown sample }}\right)-\left(\mathrm{Ct}_{\text {target gene calibrator sample }}-\right.$ $\left.\mathrm{Ct}_{\text {average of } 3 \text { endogenous control genes calibrator sample }}\right)$. Data are reported as least squares means \pm standard error of the means.

whole tissue was used to evaluate changes in gene expression throughout the lactation cycle; therefore, cellular sources of GLUT mRNA, especially during late lactation, may change according to lactation stage.

Because the lactating mammary gland is characterized by an increase in metabolic activity and hypoxia, genes regulated during hypoxic conditions also were evaluated. The oxygen-sensitive transcription factor, HIF $1 \alpha$, plays a significant role in the expression of hypoxia response element-containing genes during hypoxia, which include GLUT1 as well as VEGF (Loike et al., 1992; Sone et al., 2000). However, the gene expression of HIF1 $\alpha$ was not changed significantly throughout the sampling time points. Kallio et al. (1999) showed that the regulatory step controlling the action of HIF $1 \alpha$ occurs at the protein level, not at the level of gene expression, and mRNA expression is actually constitutive during hypoxia. Specifically within endothelial cells of humans, HIF1 $1 \alpha$ gene expression significantly changed during hypoxia (Kallio et al., 1999). Therefore, given that our data showed no alteration in gene expression, a difference could exist among species and tissue location in mRNA expression of HIF1 $\alpha$ during hypoxia. Additional studies are warranted to assess changes in HIF $1 \alpha$ protein expression in bovine mammary glands over the lactation cycle.

\section{A. VEGF}

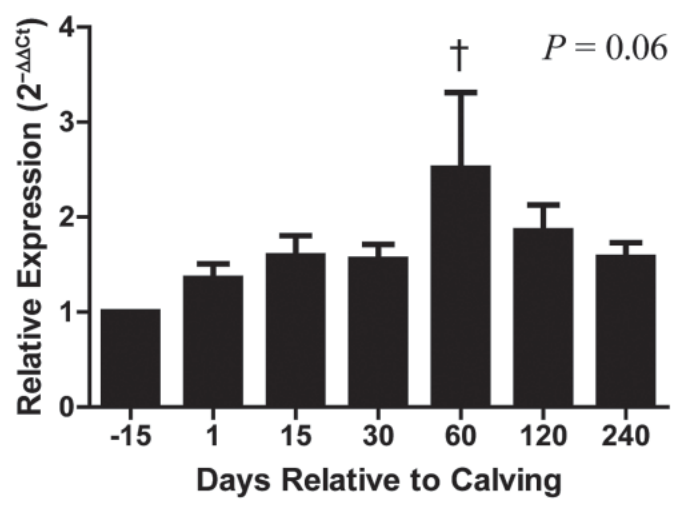

B. FLT-1

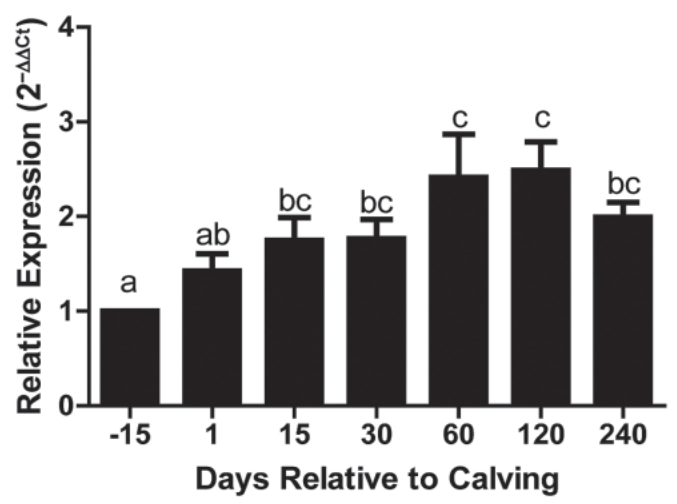

C. KDR

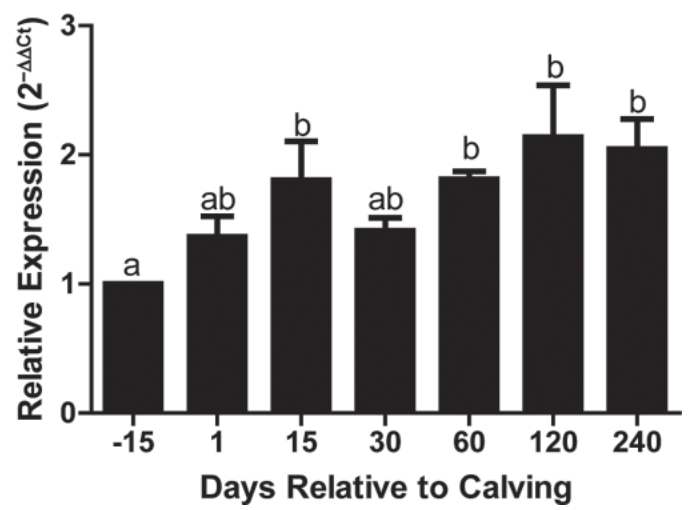

Figure 3. Alterations in mRNA abundance of (A) vascular endothelial growth factor (VEGF), (B) FMS-like tyrosine kinase (FLT-1), and $(\mathrm{C})$ kinase domain receptor $(\mathrm{KDR})$ in bovine mammary tissue obtained at $-15,1,15,30,60,120$, and $240 \mathrm{~d}$ relative to parturition $(\mathrm{n}=4)$. Data reported as least squares means \pm standard error of the means. Significant differences $(P<0.05)$ between days are represented with different letters. Data were analyzed by the $2^{-\Delta \Delta \mathrm{Ct}}$ method with $-15 \mathrm{~d}$ as the reference expression point, where $\mathrm{Ct}$ is the cycle number at which the fluorescence signal of the product crosses an arbitrary threshold set with exponential phase of the PCR and $\Delta \Delta \mathrm{Ct}$ $=\left(\mathrm{Ct}_{\text {target gene unknown sample }}-\mathrm{Ct}_{\text {average of } 3 \text { endogenous control genes unknown sample }}\right)-$ $\left(\mathrm{Ct}_{\text {target gene calibrator sample }}-\mathrm{Ct}_{\text {average of } 3 \text { endogenous control genes calibrator sample }}\right)$. 
Table 2. Pearson correlation coefficients (R) for glucose transporters (GLUT) and hypoxia-associated gene expression from transition dairy cows $(\mathrm{n}=4)$

\begin{tabular}{|c|c|c|c|c|c|}
\hline \multirow[b]{2}{*}{ GLUT } & \multirow{2}{*}{$\begin{array}{l}\text { Analysis } \\
\text { result }\end{array}$} & \multicolumn{4}{|c|}{ Hypoxia-associated gene $^{1}$} \\
\hline & & VEGF & KDR & FLT-1 & HIF- $1 \alpha$ \\
\hline GLUT1 & $\begin{array}{l}\mathrm{R} \\
P \text {-value }\end{array}$ & $\begin{array}{c}0.845 \\
<0.0001\end{array}$ & $\begin{array}{c}0.753 \\
<0.0001\end{array}$ & $\begin{array}{c}0.759 \\
<0.0001\end{array}$ & $\mathrm{NS}^{2}$ \\
\hline GLUT3 & $\begin{array}{l}\mathrm{R} \\
P \text {-value }\end{array}$ & NS & NS & $\begin{array}{l}0.443 \\
0.018\end{array}$ & NS \\
\hline GLUT4 & $\begin{array}{l}\mathrm{R} \\
P \text {-value }\end{array}$ & NS & NS & $\begin{array}{l}0.387 \\
0.042\end{array}$ & NS \\
\hline
\end{tabular}

${ }^{1}$ VEGF = vascular endothelial growth factor; KDR = kinase domain receptor; FLT-1 = FMS-like tyrosine kinase; HIF- $1 \alpha=$ hypoxia-inducible factor- $1 \alpha$.

${ }^{2} \mathrm{NS}=P>0.05$.

Both VEGF receptors, FLT-1 and KDR, showed significant increases in mRNA expression during late lactation. It is interesting to note that both receptors were significantly increased relatively early into lactation as well, which is in agreement with another study that examined gene expression and localization of FLT-1 an KDR in the mouse mammary gland (Hovey et al., 2001). Hovey et al. (2001) found an increase in mRNA abundance of both receptors in the early lactating mouse mammary gland. Additionally, when the fat pad was removed from the mammary gland before examination, expression of both receptors remained consistent throughout lactation and involution (Hovey et al., 2001). Increases in FLT-1 and KDR expression in the bovine mammary gland throughout lactation may enhance VEGF-induced responses during periods of increased metabolic activity. During late lactation, the significant increase in FLT-1 and KDR mRNA was unexpected. The present study was descriptive so authors can only postulate the reasons for this increase. Perhaps FLT- 1 and KDR mRNA is increased due to the alterations in tissue composition during lactation. Alternatively, the mammary gland may experience hypoxia during the entire lactation and not just during the transition period. Additional studies are needed to determine the mechanisms behind FLT-1 and KDR gene expression in the bovine mammary gland during late lactation.

Interestingly, even though both VEGF receptors showed significant increases in gene expression during lactation, VEGF exhibited no significant changes in gene expression. Pepper et al. (2000) identified expression of VEGF mRNA in the virgin mouse mammary gland. Additionally, FLT-1 and KDR were increased the greatest during lactation in the mouse (Pepper et al., 2000). Although the mRNA expression of VEGF did not change significantly, perhaps the increased FLT-1 and KDR expression may enhance efficiency of VEGF-mediated events during lactation. The obser- vation that bovine mammary tissues do differentially express VEGF receptors during lactation is novel and suggestive that VEGF may play an important role in regulating mammary tissue responses.

Because research in bovine mammary GLUT expression to this date focused primarily on whole-tissue and epithelial cell expression, our study examined localization patterns of GLUT from whole-tissue samples specifically within the vascular endothelium for the first time. Therefore, protein expression of GLUT and hypoxia-associated genes were examined proximal to mammary capillary beds using fluorescence microscopy. Regions containing endothelial cells were identified using cellular morphology, location of blood vessels, and a positive stain for von Willebrand factor, which is a marker for endothelial cells. Tissue regions identified as mammary capillary beds in early lactating tissue expressed GLUT1 and GLUT3 (Figure 4). The expression of GLUT4 was not detected in mammary tissue with immunohistochemistry, however, and this may be due to the insulin status of lactating dairy cows. Insulin has been shown to be dramatically decreased during lactation (Leroy et al., 2008) and, therefore, decreased GLUT4 protein expression could be reflected in this physiological adaptation. Tissues obtained during early lactation did exhibit HIF1 $\alpha$, FLT-1, and KDR localized to regions containing endothelium (data not shown). These findings were consistent with previous studies that showed endothelial cells from other species possess the capability to express these proteins (Takagi et al., 1998; Sone et al., 2000; Semenza, 2004). However, this was the first time that these genes were localized within the bovine mammary endothelium. The actual uptake of any substance from the blood is thought to be dependent on several factors, including mammary blood flow, capillary surface area, and permeability of the capillary wall. Moreover, permeability and exchange across the capillary wall can vary depending on the presence and activity of specific transmembrane transporters, 
Table 3. Pearson correlation coefficients (R) for glucose transporters (GLUT) and hypoxia-associated genes from transition dairy cows from different sampling time points post-calving $(\mathrm{n}=4)$

\begin{tabular}{|c|c|c|c|c|c|}
\hline \multirow[b]{2}{*}{ DIM } & \multirow[b]{2}{*}{ GLUT } & \multirow{2}{*}{$\begin{array}{l}\text { Analysis } \\
\text { result }\end{array}$} & \multicolumn{3}{|c|}{ Hypoxia-associated gene $^{1}$} \\
\hline & & & VEGF & KDR & HIF- $1 \alpha$ \\
\hline \multirow[t]{2}{*}{1} & \multirow[t]{2}{*}{ GLUT1 } & $\mathrm{R}$ & 0.962 & 0.980 & \multirow[t]{2}{*}{$\mathrm{NS}^{2}$} \\
\hline & & $P$-value & 0.037 & 0.019 & \\
\hline \multirow[t]{2}{*}{15} & \multirow{2}{*}{ GLUT1 } & $\mathrm{R}$ & 0.990 & 0.967 & \multirow[t]{2}{*}{ NS } \\
\hline & & $P$-value & 0.010 & 0.033 & \\
\hline \multirow[t]{2}{*}{30} & \multirow[t]{2}{*}{ GLUT1 } & $\mathrm{R}$ & 0.973 & 0.967 & \multirow[t]{2}{*}{ NS } \\
\hline & & $P$-value & 0.027 & 0.033 & \\
\hline \multirow[t]{2}{*}{60} & \multirow[t]{2}{*}{ GLUT1 } & $\mathrm{R}$ & NS & NS & \multirow{4}{*}{$\begin{array}{l}0.979 \\
0.021 \\
\text { NS }\end{array}$} \\
\hline & & $P$-value & & \multirow{3}{*}{ NS } & \\
\hline \multirow[t]{2}{*}{120} & \multirow[t]{2}{*}{ GLUT1 } & $\mathrm{R}$ & 0.967 & & \\
\hline & & $P$-value & 0.032 & & \\
\hline
\end{tabular}

${ }^{1} \mathrm{VEGF}=$ vascular endothelial growth factor; $\mathrm{KDR}=$ kinase domain receptor; HIF-1 $\alpha=$ hypoxia-inducible factor- $1 \alpha$.

${ }^{2} \mathrm{NS}=P>0.05$

which will vary for different milk constituents (Prosser et al., 1996). These principles are best illustrated by mathematical models that showed the rate of transcapillary exchange for nutrients such glucose (15-20\%) and AA (20-30\%) from arterial blood across the mammary gland was low and would actually decrease with higher mammary blood flow rates (Cant and McBride, 1995; Prosser et al., 1996; Cant et al., 2002). A potential explanation for the diffusion-limited transport of glucose observed in the mammary gland at normal or high blood flow rates may be due to the presence and activity of GLUT on mammary endothelial and epithelial cells. Whereas previous studies have focused solely on the potential role of GLUT-mediated uptake by mammary epithelial cells, these descriptive studies suggest for the first time that glucose transporters also may play a role at the level of mammary endothelium.

The expression and function of GLUT, specifically on mammary endothelial cells, was assessed using an in vitro culture system. The presence of GLUT1, GLUT3, and GLUT4 on BMEC were confirmed using isotypespecific antibodies and fluorescence microscopy. Moreover, GLUT were functional as assessed using a glucose uptake assay and specific GLUT inhibitor that significantly decreased glucose uptake in BMEC. Gaudreault et al. (2008) also found a significant decrease in glucose uptake using human coronary endothelial cells with the addition of cytochalasin B. However, both here and in
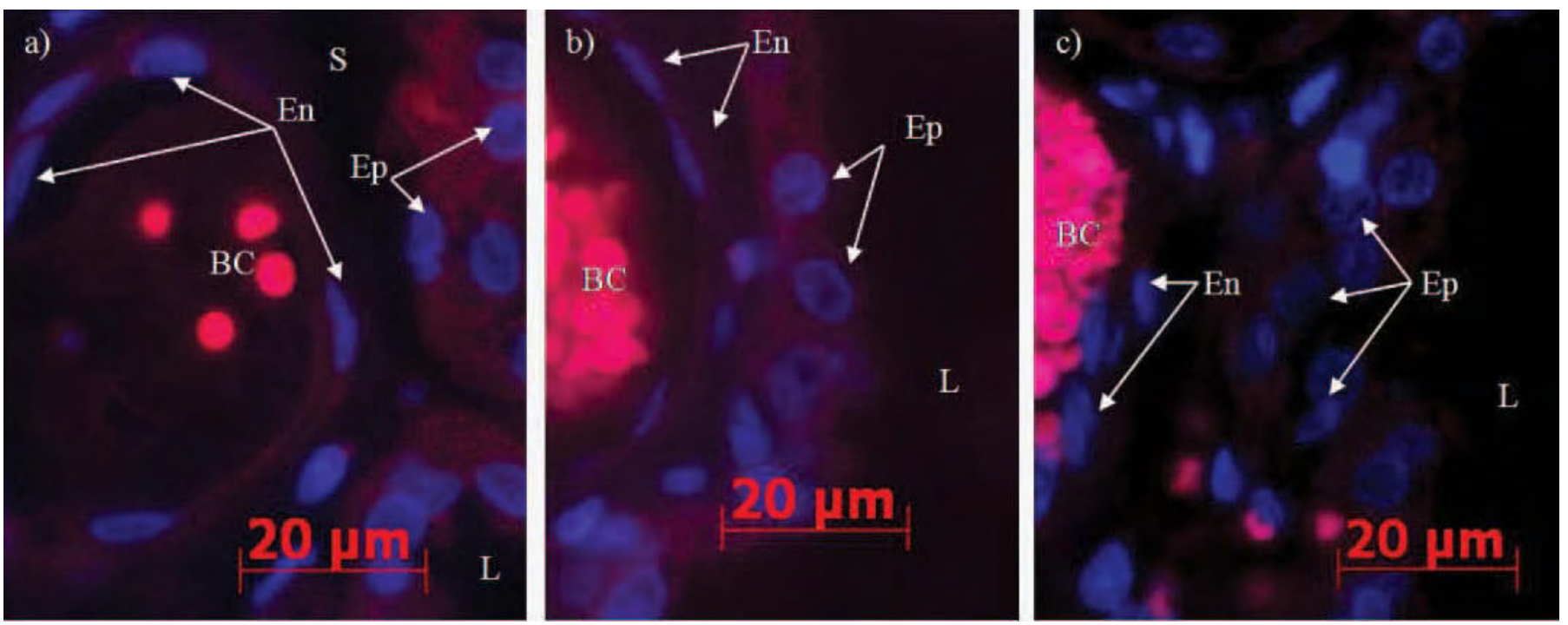

Figure 4. Fluorescent detection of glucose transporters (GLUT) on whole mammary tissue. (a,b) Detection of GLUT1 and GLUT3 (red, on endothelial and epithelial cells), respectively, on whole tissue; 4',6-diamidino-2-phenylindole [DAPI (blue); P36935; Invitrogen, Carlsbad, CA] indicates nuclei. (c) Negative control for NovaRED (Vector Laboratories, Burlington, CA) substrate. BC = blood cells; Ep = epithelial cells; En $=$ endothelial cells; $\mathrm{L}=$ lumen; $\mathrm{S}=$ stroma. Color version available in the online PDF. 

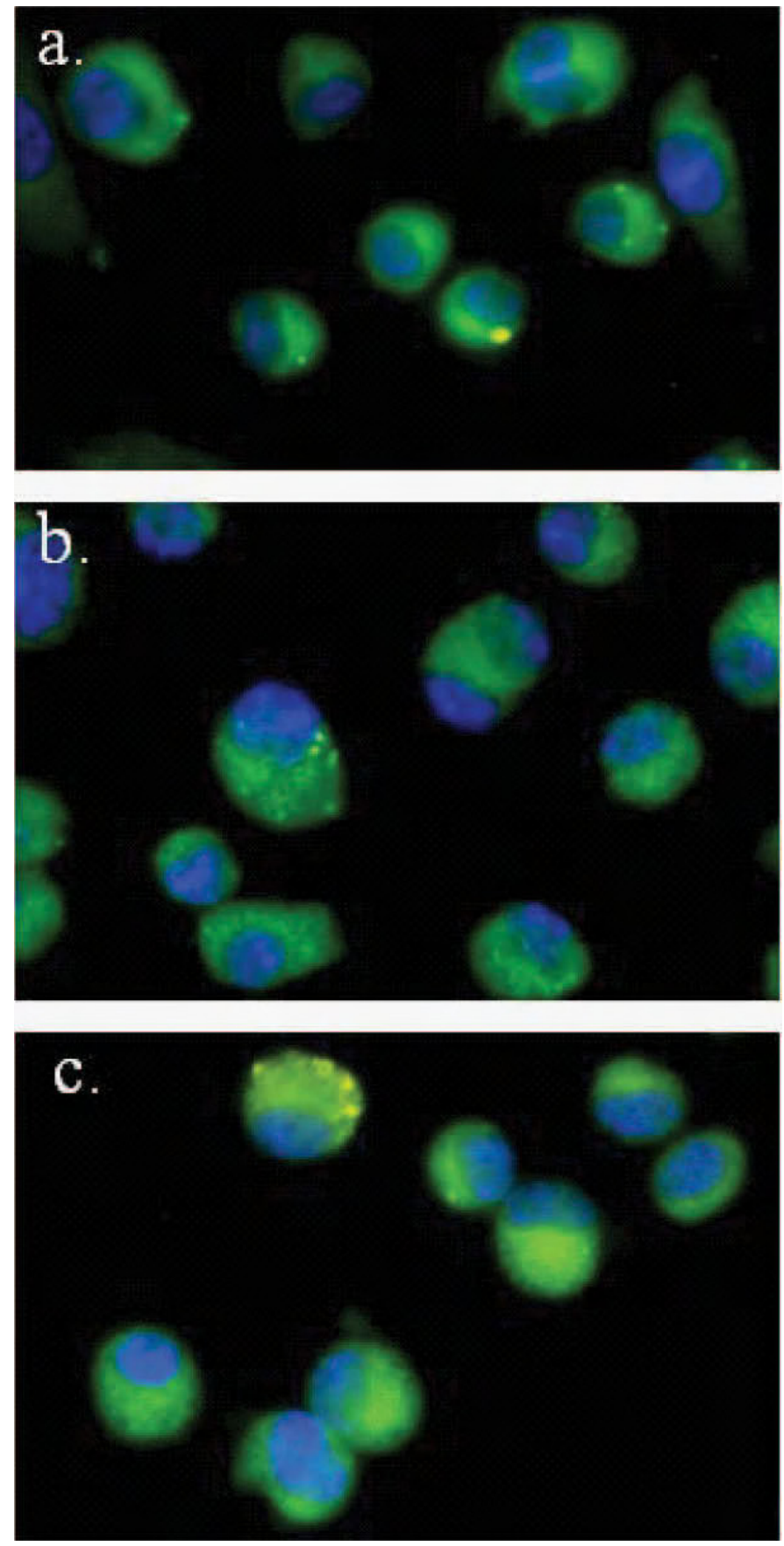

Figure 5. Fluorescent detection of glucose transporters (GLUT) on primary bovine mammary vascular endothelial cells (BMEC). $(\mathrm{a}, \mathrm{b}, \mathrm{c})$ Detection of GLUT1, GLUT3, and GLUT4 (green), respectively, on BMEC; 4',6-diamidino-2-phenylindole [DAPI (blue); P36935; Invitrogen, Carlsbad, CA] indicates nuclei. Color version available in the online PDF.

the previous study, glucose uptake was not completely abolished. Gaudreault et al. (2008) accredited this phenomenon to the fact that cytochalasin B is ineffective at blocking glucose transport via sodium-dependent GLUT SGLT1. This, too, could be the case in the dairy

\section{2-NBDG Uptake}

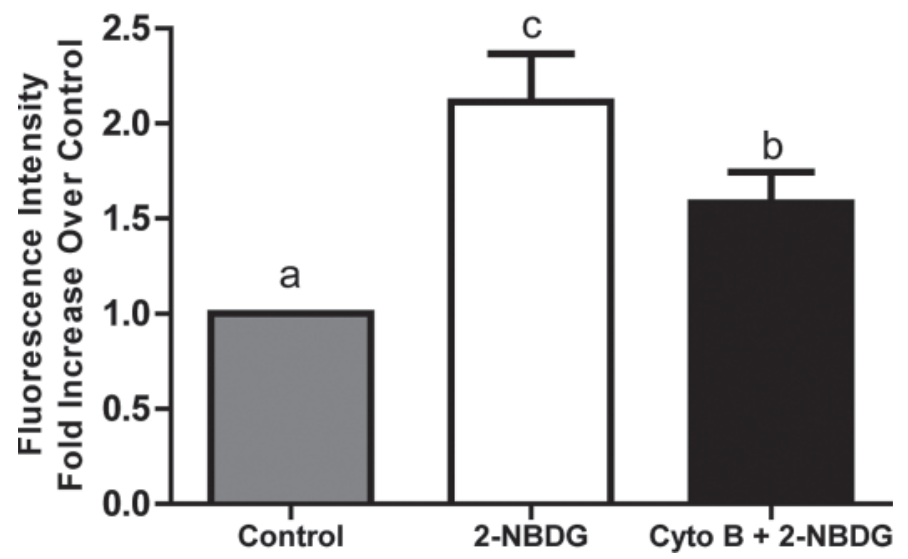

Figure 6. Inhibition of glucose uptake in cultured bovine mammary vascular endothelial cells (BMEC). Significant inhibition of 2-(N-(7nitrobenz-2-oxa-1,3-diazol-4-yl)amino)-2-deoxyglucose (2-NBDG) uptake with addition of glucose transporter (GLUT) inhibitor, $10 \mu M$ cytochalasin $\mathrm{B}$ (CytoB; $P=0.05$ ). Results are expressed as fold increase of either 2-NBDG or CytoB + 2-NBDG over the control that was not treated with $2-\mathrm{NBDG}$. ${ }^{\mathrm{a}, \mathrm{b}, \mathrm{c}}$ Means $(\mathrm{n}=6)$ without a common letter differ significantly $(P<0.05)$.

cow and interestingly, SGLT1 was previously identified in the bovine mammary gland (Zhao and Keating, 2007). Further research is needed to determine the role of different GLUT in the context of bovine mammary endothelial cell function.

\section{CONCLUSIONS}

Because glucose utilization is essential in supporting the onset and maintenance of milk secretion, it is necessary to understand the mechanisms of glucose transport from the blood and into the interstitial spaces within the mammary tissue. In the past, epithelial cells were the primary focus of GLUT expression and glucose uptake experiments during lactation. In this study, however, BMEC were shown for the first time to not only express GLUTs, but also utilize these transporters, in part, to take up glucose. Hypoxia-associated genes were characterized because they may exert some control overexpression of GLUTs during periods of increased metabolic function. This study showed for the first time that some hypoxia-associated genes were positively correlated with GLUT mRNA expression. These genes may prove to be important regulators of GLUT expression and glucose uptake in the mammary gland during times of increased metabolic activity. Given that BMEC express glucose transporters that are functional, further research to determine the mechanisms that regulate glucose transport from the blood into the mammary gland is warranted. 


\section{ACKNOWLEDGMENTS}

This work was supported, in part, by a grant from the USDA NRI Competitive Grants program (200735204-18463) and from the Michigan Milk Producers Association.

\section{REFERENCES}

Abdul Awal, M., M. Matsumoto, Y. Toyoshima, and H. Nishinakagawa. 1996. Ultrastructural and morphometrical studies on the endothelial cells of arteries supplying the abdomino-inguinal mammary gland of rats during the reproductive cycle. J. Vet. Med. Sci. 58:29-34.

Aherne, K. M., M. R. Davis, and L. M. Sordillo. 1995. Isolation and characterization of bovine mammary endothelial cells. Methods Cell Sci. 17:41-46.

Bickerstaffe, R., E. F. Annison, and J. L. Linzell. 1974. The metabolism of glucose, acetate, lipids and amino acids in lactating dairy cows. J. Agric. Sci. 82:71-85.

Bionaz, M., and J. J. Loor. 2007. Identification of reference genes for quantitative real-time PCR in the bovine mammary gland during the lactation cycle. Physiol. Genomics 29:312-319.

Cant, J. P., and B. W. McBride. 1995. Mathematical analysis of the relationship between blood flow and uptake of nutrients in the mammary glands of a lactating cow. J. Dairy Res. 62:405-422.

Cant, J. P., D. R. Trout, F. Qiao, and N. G. Purdie. 2002. Milk synthetic response of the bovine mammary gland to an increase in the local concentration of arterial glucose. J. Dairy Sci. 85:494-503.

Estensen, R. D., and P. G. W. Plagemann. 1972. Cytochalasin B: Inhibition of glucose and glucosamine transport. Proc. Natl. Acad. Sci. USA 69:1430-1434.

Ferrara, N., H.-P. Gerber, and J. LeCouter. 2003. The biology of VEGF and its receptors. Nat. Med. 9:669-676.

Gaudreault, N., D. R. L. Scriven, I. Laher, and E. D. W. Moore. 2008. Subcellular characterization of glucose uptake in coronary endothelial cells. Microvasc. Res. 75:73-82.

Herbein, J. H., R. J. Aiello, L. I. Eckler, R. E. Pearson, and R. M. Akers. 1985. Glucagon, insulin, growth hormone, and glucose concentrations in blood plasma of lactating dairy cows. J. Dairy Sci. $68: 320-325$.

Hovey, R. C., A. S. Goldhar, J. Baffi, and B. K. Vonderhaar. 2001 Transcriptional regulation of vascular endothelial growth factor expression in epithelial and stromal cells during mouse mammary gland development. Mol. Endocrinol. 15:819-831.

Kallio, P. J., W. J. Wilson, S. O'Brien, Y. Makino, and L. Poellinger. 1999. Regulation of the hypoxia-inducible transcription factor 1alpha by the ubiquitin-proteasome pathway. J. Biol. Chem. 274:6519-6525.

Komatsu, T., F. Itoh, S. Kushibiki, and K. Hodate. 2005. Changes in gene expression of glucose transporters in lactating and nonlactating cows. J. Anim. Sci. 83:557-564.

Leroy, J. L., T. Vanholder, A. T. M. Van Knegsel, I. Garcia-Ispierto, and P. E. J. Bols. 2008. Nutrient prioritization in dairy cows early postpartum: Mismatch between metabolism and fertility? Reprod. Domest. Anim. 43:96-103.

Livak, K. J., and T. D. Schmittgen. 2001. Analysis of relative gene expression data using real-time quantitative PCR and the $2^{-\Delta \Delta \mathrm{Ct}}$ method. Methods 25:402-408.

Loike, J. D., L. Cao, J. Brett, S. Ogawa, S. C. Silverstein, and D. Stern. 1992. Hypoxia induces glucose transporter expression in endothelial cells. Am. J. Physiol. 263:C326-C333.
Ludewig, T. 1996a. Electron microscopic study of cells of the lactating bovine mammary gland. Tierarztl. Prax. 24:11-16. (Article in German)

Ludewig, T. 1996b. Light and electron microscopic investigations of the blood-milk barrier in lactating cow udders. Anat. Histol. Embryol. 25:121-126. (Article in German)

Matsumoto, M., H. Nishinakagawa, M. Kurohmaru, Y. Hayashi, and J. Otsuka. 1992. Pregnancy and lactation affect the microvasculature of the mammary gland in mice. J. Vet. Med. Sci. 54:937-943.

Naccarato, A. G., P. Viacava, G. Bocci, G. Fanelli, P. Aretini, A. Lonobile, G. Montruccoli, and G. Bevilacqua. 2003. Definition of the microvascular pattern of the normal human adult mammary gland. J. Anat. 203:599-603.

Pantaleon, M., M. B. Harvey, W. S. Pascoe, D. E. James, and P. L. Kaye. 1997. Glucose transporter GLUT3: Ontogeny, targeting, and role in the mouse blastocyst. Proc. Natl. Acad. Sci. USA 94:3795-3800

Pepper, M. S., D. Baetens, S. J. Mandriota, C. Di Sanza, S. Oikemus, T. F. Lane, J. V. Soriano, R. Montesano, and M. L. Iruela-Arispe. 2000. Regulation of VEGF and VEGF receptor expression in the rodent mammary gland during pregnancy, lactation, and involution. Dev. Dyn. 218:507-524.

Prosser, C. G., S. R. Davis, V. C. Farr, and P. Lacasse. 1996. Regulation of blood flow in the mammary microvasculature. J. Dairy Sci. 79:1184-1197.

Reynolds, M. 1967. Mammary respiration in lactating goats. Am. J. Physiol. 212:707-710.

Royer, C., J. Lachuer, G. Crouzoulon, J.-C. Roux, J. Peyronnet, J. Mamet, J.-M. Pequignot, and Y. Dalmaz. 2000. Effects of gestational hypoxia on mRNA levels of Glut3 and Glut4 transporters, hypoxia inducible factor-1 and thyroid hormone receptors in developing rat brain. Brain Res. 856:119-128.

Semenza, G. L. 2004. Hydroxylation of HIF-1: Oxygen sensing at the molecular level. Physiology (Bethesda) 19:176-182.

Sone, H., B. K. Deo, and A. K. Kumagai. 2000. Enhancement of glucose transport by vascular endothelial growth factor in retinal endothelial cells. Invest. Ophthalmol. Vis. Sci. 41:1876-1884.

Sordillo, L. M., and S. C. Nickerson. 1988. Morphologic changes in the bovine mammary gland during involution and lactogenesis. Am. J. Vet. Res. 49:1112-1120.

Stirling, J. W., and J. A. Chandler. 1976. The fine structure of the normal, resting terminal ductal-lobular unit of the female breast. Virchows Arch. A Pathol. Anat. Histol. 372:205-226.

Takagi, H., G. L. King, and L. P. Aiello. 1998. Hypoxia upregulates glucose transport activity through an adenosine-mediated increase of GLUT1 expression in retinal capillary endothelial cells. Diabetes $47: 1480-1488$

Takata, K., and H. Hirano. 1997. Mechanism of glucose transport across the human and rat placental barrier: A review. Microsc. Res. Tech. 38:145-152.

Threadgold, L. C., and N. J. Kuhn. 1979. Glucose-6-phosphate hydrolysis by lactating rat mammary gland. Int. J. Biochem. 10:683685.

Zhao, F.-Q., W. T. Dixon, and J. J. Kennelly. 1996. Localization and gene expression of glucose transporters in bovine mammary gland. Comp. Biochem. Physiol. B Biochem. Mol. Biol. 115:127-134.

Zhao, F. Q., D. R. Glimm, and J. J. Kennelly. 1993. Distribution of mammalian facilitative glucose transporter messenger RNA in bovine tissues. Int. J. Biochem. 25:1897-1903.

Zhao, F. Q., and A. F. Keating. 2007. Expression and regulation of glucose transporters in the bovine mammary gland. J. Dairy Sci. 90(Suppl. 1):E76-E86 